\title{
Protección tecnológica y contractual de las obras con derecho de autor: ¿ H acia una privatización del acceso a la información?
}

\section{J. Carlos Fernández-M olina \\ Doctor en Documentación y Licenceiado en Derecho por la Universidad de Granada. Profesor Titular de la Facultad de Biblioteconomia y D ocumentación, U niversidad de G ranada, España. E-mail: jcfernan@ugr.es}

\begin{abstract}
Resumen
Los problemas que el gran desarrollo de la información digital e Internet están provocando al derecho de autor se están intentando solucionar a través de tres vías: legislativa, tecnológica y contractual. La protección proporcionada a las obras con derecho de autor mediante medidas tecnológicas complementa a las condiciones de uso establecidas en las licencias $y$, además, ambos tipos de protección están respaldados por las nuevas leyes surgidas para adaptarse al nuevo contexto tecnológico. Como resultado de esta triple protección se están poniendo en grave peligro las excepciones y limitaciones a los derechos de autor reconocidas por las leyes de derecho de autor para beneficiar a las bibliotecas, sus usuarios y los ciudadanos en general, dando lugar a una fuerte y peligrosa privatización del acceso a la información.
\end{abstract}

\section{Palabras clave}

Derecho de autor; Medidas tecnológicas; Licencias; Límites al derecho de autor.

Technological and contractual protection of copyrighted works: Toward a privatization of information access?

\begin{abstract}
The problems that the rapid development of digital information and the Internet are

causing for copyright are being solved in three directions: legal, technological and contractual. The protection given to copyrighted works by technological means complements the conditions of use established in the licences; moreover, both types of protection are backed up by the new laws arising for adaptation to the current technological context. As a result of this triple protection, we are risking the limitations to copyright acknowledged by copyright laws in the benefit of libraries, library users and citizens in general, giving way to a dangerous privatization of access to information.
\end{abstract}

\section{Keywords}

Copyright; Technological measures; Licenses; Copyright limitations.

\section{INTRODUCCIÓN}

El enorme desarrollo de la informática y las telecomunicaciones ha dado lugar a la aparición del entorno digital, que ha supuesto un cambio drástico en las condiciones deacceso, distribución y uso de las obras intelectuales: ahora es posible acceder a las obras digitales de forma casi instantánea, desde cualquier lugar y en cualquier momento; y su creación, difusión y modificación es muy fácil, pudiendo hacer copias múltiples con la misma calidad que el original y prácticamente sin coste. En definitiva, "lo digital es diferente", tanto para los propietarios de los derechos de autor como para los usuarios de las obras.

Para hacer frente a esta nueva situación se están desarrollando tres diferentes tipos de soluciones: legislativa, tecnológica y contractual. La primera deellas, la vía legislativa, consiste en modificar las leyes de derecho de autor para adaptarlas a la nueva realidad. Teniendo en cuenta el carácter transnacional de la transmisión y uso de las obras intelectuales en formato digital, esta solución se está afrontando desde una perspectiva internacional, por lo quese está produciendo en los últimos años un evidente proceso de armonización internacional de todo lo relacionado con el derecho de autor, de manera que las diferencias actualmente existentes entre las legislaciones de los diferentes países van a ir disminuyendo sensiblemente en los próximos años, incluso entre los que pertenecen a diferentes tradiciones jurídicas (latino-continental o anglosajona). En cuanto a la solución tecnológica, consiste en sistemas que identifican las obras intelectuales y controlan el uso que se hace de ellas: marcas de agua digitales que identifican la obra, programas que detectan si se hacen alteraciones en la obra, que impiden la copia, que siguen la pista de su movimiento a través de la red, que contabilizan cada uso, etc. Por último, la solución contractual tiene su origen en el hecho de que, a diferencia de las obras impresas, las obras digitales no se suelen comprar, sino que sólo pueden ser utilizadas de acuerdo con lo establecido en las licencias, esto es, contratos entre dos partes: el editor/ productor y el usuario, ya sea personal o institucional (biblioteca, centro de información, universidad, etc.). Estos tres tipos de soluciones no llevan caminos totalmente independientes, sino que se 
complementan entre sí. Por tanto, las condiciones de acceso y uso de las obras digitales no sólo van a estar determinadas por las nuevas leyes de derecho de autor de cada país, sino también por los sistemas tecnológicos implementados para protegerlas y por lo establecido en las correspondientes licencias.

Todas las leyes nacionales de derecho de autor intentan establecer un equilibrio adecuado entre los intereses de los autores, los de los explotadores comerciales de las obras y los de los usuarios. Para ello incluyen una serie de límites a los derechos de autor, de manera que éstos no tengan carácter absoluto, lo que se traduce en la práctica en que la duración de estos derechos es limitada ( 70 años tras el fallecimiento del autor, como norma general) y en que en determinadas ocasiones la obra puede ser usada de manera gratuita y sin autorización del poseedor delos derechos. Esteúltimo tipo de límites es muy diverso y variado, pero a nosotros nos interesan especialmente dos: por un lado, la copia privada (en los países de tradición jurídica latino-continental) y su casi equivalente fair use/ dealing de los países anglosajones, y por otro, los privilegios de las bibliotecas einstituciones similares. Pues bien, este equilibrio, tradicionalmente bien resuelto en las leyes de derecho deautor, está siendo puesto en serio peligro debido a la utilización actual de las otras dos vías de regulación: tecnológica y contractual. En concreto, el peligro se encuentra en que a través de tales licencias y medidas tecnológicas queden invalidados (legalmente y/ o en la práctica) los privilegios que las leyes de derecho de autor reconocen a las bibliotecas, sus usuarios y los ciudadanos en general.

El objetivo de este trabajo es, por tanto, analizar en qué medida están bajo amenaza tales límites y privilegios por la acción conjunta deestas tres formas de protección. Para ello, comenzaremos haciendo un breve repaso de cuáles son los principales límites al derecho de autor, su justificación y condiciones de aplicación, como punto de partida imprescindible para analizar a continuación cuáles son los principales problemas que plantean los sistemas tecnológicos, las licencias y la regulación de ambos en las nuevas leyes.

\section{Los límites al derecho de autor}

El Convenio de Berna (OMPI, 1971) es el tratado internacional que recoge los principales límites al derecho de autor $y$, aunque ha sido ratificado por la gran mayoría de los países del mundo (150 en la actualidad), éstos tienen total soberanía para decidir si los incluyen y en qué medida en sus leyes nacionales.
Como consecuencia, nos encontramos con una enorme variedad de formas de incluir los límites al derecho de autor en las diferentes leyes nacionales.

Para un mejor análisis de su contenido e implicaciones, todos estos límites pueden ser agrupados en cuatro categorías de acuerdo con las razones que los justifican (Guibault, 2000): 1) la defensa de derechos fundamentales; 2) derecho de la competencia; 3) el interés público; y 4) "fallos del mercado". L os límites más numerosos eimportantes son, sin duda, los basados en la protección de determinados derechos fundamentales de los individuos: la libertad de expresión y el derecho a la información, por un lado, y el derecho a la intimidad, por el otro.

El artículo 19 de la Declaración Universal de los Derechos H umanos (N aciones U nidas, 1948) reconoce la libertad de opinión y expresión y el derecho a buscar, recibir y comunicar información. Además, su artículo 27, precisamente el que reconoce los derechos de autor, también reconoce el derecho a participar libremente en la vida cultural de la comunidad. Esto supone que hay que encontrar un equilibrio entre los intereses de los creadores y poseedores de los derechos sobre las obras intelectuales y los del público en general, con el objetivo de facilitar el libre flujo de información en la sociedad. Son muy diversos los límites cuyo origen es la defensa de estos derechos. Entre otros: el derecho de citar las obras para fines de estudio, crítica o polémica (artículo 46, III de la ley brasileña (Brasil, 1998), el derecho a reproducir en los medios de comunicación impresos informes, noticias o artículos de temas de actualidad aparecidos en otros medios ( art. 46,1, a) ), derecho a reproducir o hacer disponibles al público los discursos de carácter político (art. $46, \mathrm{I}$, b)) con objeto de crítica, el derecho a reproducir obras con propósitos de parodia (art. 47).

En cuanto a la protección del derecho a la intimidad, es uno de los fundamentos básicos de la copia privada, probablemente el límite más importante en los países de tradición jurídica latina. Este límite, reconocido en la gran mayoría de las legislaciones nacionales (en la ley brasileña en su artículo 46, II), se basa tanto en que el derecho de autor no debe entrar en la esfera privada del individuo como en el hecho de que el uso privado de las obras no afecta a los intereses de los propietarios de los derechos de autor, aunque esto último ya no es tan cierto desde la aparición de medios tecnológicos que permiten la explotación privada deforma masiva (videos, xerocopias, CD s, etc.). 


\section{J. C arlos Fernández-M olina}

Los límites basados en el derecho de la competencia, cuyo objetivo es evitar cualquier posición dominante dentro de la industria correspondiente, son habituales en el campo de las bases de datos y en el de los programas de ordenador. Por ejemplo, la directiva europea sobre programas deordenador (U nión Europea, 1991) permite, sin autorización del propietario de los derechos, hacer una copia deseguridad o reproducir y traducir el código en la medida necesaria para conseguir interoperabilidad. Reglas similares establece también la directiva sobre bases de datos (U nión Europea, 1996). También parecida es la regulación establecida en la $\mathrm{D}$ igital M illennium Copyright Act estadounidense (Estados U nidos, 1998), cuando permite eludir las medidas tecnológicas de protección con propósito de ingeniería inversa.

$M$ ás habituales que los anteriores son los límites basados en razones de interés público, como por ejemplo la promoción de la educación y la cultura. Así, es habitual que se concedan ciertos privilegios a las instituciones educativas, lo que les permite reproducir partes de las obras o comunicarlas a través de la radio o televisión siempre que sea en actividades educativas sin ánimo de lucro. D entro de esta categoría de límites se encuentra el que es, sin duda, el más importante para los profesionales de la información: los denominados privilegios de bibliotecas e instituciones similares (museos, archivos, filmotecas, etc.). Estos límites, recogidos de forma muy completa y detallada en las legislaciones de los países anglosajones (Estados U nidos y el Reino U nido son buenos ejemplos) y no tanto en los países latino-continentales ( por ejemplo, la legislación brasileña no los recoge), permiten que las bibliotecas puedan facilitar a sus usuarios copias de un artículo 0 de una pequeña porción de una obra, copiar obras completas por razones dearchivo o preservación, prestar las obras a sus usuarios o a otras bibliotecas, etc. Por último, también vale la pena mencionar otros límites habitualmente recogidos en las leyes de derecho de autor: los que permiten reproducir las obras por parte de personas con deficiencia visual (art. $46,1, d$ ) de la ley brasileña) o auditiva, o para propósitos administrativos o judiciales (art. 46, VII).

Otros límites al derecho de autor han sido implementados debido a los "fallos del mercado" en la producción y explotación de las obras intelectuales, lo quesucedecuando es muy difícil o excesivamente costosa la negociación entre las partes (propietarios de derechos y usuarios) o impedir de forma efectiva los usos no autorizados ( $G$ ordon, 1982). En tales circunstancias, la eficiencia económica demanda formas alternativas, en especial las licencias no voluntarias, como las establecidas para compensar las pérdidas para los titulares de los derechos de autor provocadas por las copias domésticas de películas de video o degrabaciones musicales. Este tipo de límites está siendo atacado ( solicitando su eliminación) en la actualidad debido a la aparición de los nuevos sistemas degestión electrónica de los derechos deautor, ya que éstos permiten licenciar directamente el uso de las obras e impedir los usos no autorizadosa las misma (M erges, 1997; Bell, 1998). No obstante, a los que abogan por esta eliminación habría que recordarles que los límites que permiten las copias privadas de las obras, ya sean impresas, audiovisuales, sonoras o digitales, no sólo están basadas en los "fallos del mercado" sino también en el derecho fundamental a la intimidad, como ya hemos visto previamente.

Independientemente decual sea su justificación, cualquier limitación a los derechos de autor tiene que superar el test de los "tres pasos o fases", establecido por primera vez en el art 9.2 del Convenio de Berna y recogido posteriormente por el Acuerdo ADPIC de la Organización M undial del Comercio (OM C, 1994) y por los dos nuevos tratados de la O rganización $M$ undial dela Propiedad Intelectual (O M PI, 1996a, 1996b). Estos tres pasos o condiciones, de carácter acumulativo, son: a) en determinados casos especiales, b) que no atentea la explotación normal dela obra, c) ni causeun perjuicio injustificado a los intereses legítimos del autor.

Los dos tratados de la OM PI de 1996 constituyen el punto de partida de las reformas de las leyes nacionales de derecho de autor para adaptarlas al entorno digital, por lo que su tratamiento de los límites al derecho de autor es especialmenteimportante. Los dos artículos que los regulan (el 10 del TDA y el 16 del TIEF) parten de la misma idea básica: hay que respetar lo establecido en el Convenio de Berna y en el Acuerdo sobre los AD PIC. Centrándonos en el artículo 10 del TDA, en su primer párrafo establece que las partes pueden establecer excepciones a los derechos previstos en él "en ciertos casos especiales que no atenten a la explotación normal de la obra ni causen perjuicio injustificado a los intereses legítimos del autor", con lo que repite la fórmula de las tres fases contenida en el art. 9.2 del Convenio de Berna y el 13 de los AD PIC. D urante la conferencia surgió la idea de que había que mantener el nivel de exigencia en el control de los límites, pero sin permitir a su vez una preponderancia absoluta de los intereses de los titulares de los derechos, lo que se tradujo en que el artículo 10 finalmente aprobado, junto con su Declaración Concertada (que lo complementa y ayuda a su 
Protección tecnológica y contractual de las obras con derecho de autor: ¿H acia una privatización del acceso a la información?

interpretación), resulta bastante más moderado que el inicial artículo 12 del proyecto. U n elemento clave para esta afirmación es la formulación del preámbulo de este tratado, que expresamente reconoce "la necesidad de mantener un equilibrio entre los derechos de los autores y los intereses del público en general, en particular en la educación, la investigación y el acceso a la información, como se refleja en el Convenio de Berna". Este preámbulo es importante, ya quecorrige en partela creciente tendencia (plasmada en los ADPIC) de poner toda la regulación de la propiedad intelectual al servicio de los intereses comerciales, dejando a un lado el resto deintereses y consideraciones (O man, 1994).

Igualmente importantes son el párrafo segundo del artículo 10 y su D eclaración Concertada. Tras la adopción de los AD PIC, se planteó la duda de si era posible la creación de nuevos límites a los derechos previstos en el Convenio de Berna. En respuesta a dicho debate, el art. 10.2 consigna expresamentela necesidad de que los Estados, cuando apliquen el Convenio de Berna, cumplan con la regla de los tres pasos para todos los derechos previstos en el Convenio y no sólo con respecto al derecho de reproducción: "al aplicar el Convenio de Berna, las Partes Contratantes restringirán cualquier limitación o excepción impuesta a los derechos previstos en dicho Convenio a ciertos casos especiales que no atenten a la explotación normal de la obra ni causen un perjuicio injustificado a los intereses legítimos del autor".

Así se reitera también en el segundo párrafo de la Declaración Concertada del art. 10, al decir que "también queda entendido queel artículo 10.2 no reduce ni amplía el ámbito de aplicabilidad de las limitaciones y excepciones permitidas por el Convenio deBerna". Pero esto no quiere decir que la materia de los límites quede "congelada" (G arrote, 2001) en Internet, ya que en el primer párrafo de la D eclaración Concertada del art. 10 expresamente seacuerda quelos Estados pueden "aplicar y ampliar debidamente las limitaciones y excepciones al entorno digital" en sus legislaciones nacionales, y que pueden establecer "nuevas excepciones y limitaciones que resulten adecuadas al entorno de red digital". Es decir, se prevé expresamentequese puedan crear nuevos "límites o excepciones I nternet", claro está, dentro de lo marcado por el art. 10.2 y en concreto de la prueba de las tres fases. En definitiva, los tratados O M PI no suponen una disminución de los límites al derecho de autor, sino una simple adaptación a las nuevas circunstancias del entorno digital.

Ci. Inf., Brasília, v. 32, n. 2, p. 54-63, maio/ago. 2003

\section{LAS MEDIDAS TECNOLÓGICAS DE PROTECCIÓN}

La vía tecnológica de protección de las obras intelectuales consiste en utilizar una serie de mecanismosque permiten identificar los materiales susceptibles de ser protegidos por los derechos de autor y que controlan el uso que se hacede éstos, evitando pérdidas económicas para quienes ostentan los derechos de explotación así como la violación de los derechos morales (Fernández-M olina \& Peis, 2001) de sus autores. Estos sistemas, que reciben diversas denominaciones - ECM S (Electronic Copyright $M$ anagement Systems), ERM S (Electronic Rights $M$ anagement Systems) O DRMS (Digital Rights $M$ anagement Systems) - , permiten ahora la utilización de barreras, cercados o vallas, es decir, métodos de protección de la propiedad habituales en otros sectores, pero que hasta ahora no eran técnicamente posibles para los derechos de autor (O 'Rourke, 1998).

La protección legal de estos sistemas tecnológicos también tiene su punto de partida en los dos tratados O M PI de 1996, en concreto en sus artículos 11 y 18, respectivamente. El artículo 11 del TDA, titulado "O bligaciones relativas a las medidas tecnológicas", establece que: "L as Partes Contratantes proporcionarán protección jurídica adecuada y recursos jurídicos efectivos contra la acción de eludir las medidas tecnológicas efectivas que sean utilizadas por los autores en relación con el ejercicio de sus derechos en virtud del presente Tratado o del Convenio de Berna y que, respecto de sus obras, restrinjan actos que no estén autorizados por los autores concernidos o permitidos por la Ley".

Su contenido fundamental podemos resumirlo de la forma siguiente. Los países firmantes de este tratado deberán proteger legalmente las medidas tecnológicas: a) "efectivas" (concepto quetendrá que definirseen cada ley nacional); b) usadas por los autores para el ejercicio de sus derechos de autor (reconocidos tanto por este tratado como por el Convenio de Berna); y c) que restrinjan actos que no estén autorizados por los autores o permitidos por la ley (lo que permite conjugar el respeto de las medidas tecnológicas con los límites a los derechos de autor, ya que, como aclara Koelman (2000), supone que no está prohibida la elusión de las medidas tecnológicas para llevar a cabo actos permitidos en base a alguno detales límites). Pero además de las condiciones para que las medidas tecnológicas sean protegidas legalmente, hay una cuestión fundamental que queda confusa e irresuelta en esteartículo: ¿quéactos prohíbe? $H$ ay tres posibles enfoques ( $D$ eW erra, 2001): a) el acto 


\section{J. C arlos Fernández-M olina}

de elusión en sí mismo, es decir, será responsable aquél que eluda la medida tecnológica; b) el tráfico/comercio/ suministro delos dispositivos tecnológicos que permiten la elusión, lo que se ha denominado como "actividades preparatorias", de manera que será responsable quien venda o facilite a otros los medios para la elusión; c) ambas posibilidades. Como veremos a continuación, las leyes que han desarrollado este artículo han adoptado soluciones diversas en este punto.

$\mathrm{H}$ asta ahora, son muy escasas las normas jurídicas que han implementado esta protección de las medidas tecnológicas establecidas en el artículo 11 del TDA, aunquees previsible queen los próximos años la mayoría de los países sean parte de este nuevo tratado y, en consecuencia, tengan quemodificar sus leyes de derecho de autor para proteger tales medidas tecnológicas. Las principales leyes que lo han implementado son la ya mencionada Digital Millennium Copyright Act estadounidense (en adelante DM CA), la Copyright Amendment (D igital Agenda) Act australiana (Australia, 2000) y la D irectiva europea de derecho de autor en la sociedad de la información (U nión Europea, 2001). Un caso especial es Brasil, ya queaunque todavía no es parte de ninguno de los dos tratados O M PI de 1996, sí que incluyó en la reforma de su ley de derecho de autor de 1998 un artículo, el 107, en el que se regulan las medidas tecnológicas. U $\mathrm{n}$ análisis pormenorizado de estas leyes sobrepasa ampliamente los objetivos de esteartículo, por lo que aquí vamos simplemente a pasar revista a los aspectos más significativos de cada una de ellas en lo que respecta a la regulación de las medidas tecnológicas.

La D M CA estadounidense es la ley que ha marcado en buena medida el camino a seguir por otros países. Esta ley añade un nuevo capítulo 12 a la ley de derecho de autor estadounidensey, en lo querespecta a la protección de las medidas tecnológicas, le dedica su sección 1201. Esta sección se estructura de acuerdo con una división esencial, en función de que se trate de medidas tecnológicas que controlan el acceso a las obras o que protegen los derechos deautor. Así, el acceso no autorizado a la obra se prohíbe a través de la prohibición tanto del mero acto de elusión como del comercio y tráfico de dispositivos de elusión (las denominadas "actividades preparatorias"). Sin embargo, en lo que se refiere a las medidas tecnológicas que protegen los derechos de autor, esta ley no prohíbe el acto en sí mismo de eludirlas sino sólo las "actividades preparatorias", decisión tomada por el legislador estadounidense con el objetivo de no penalizar usos potenciales no infractores como, por ejemplo, los incluidos bajo el fair use.
En cuanto a las excepciones a esas prohibiciones, la DM CA no contenía ninguna en su redacción originaria, pero durante el trámite legislativo se fueron añadiendo algunas en función de la capacidad de presión de los distintos grupos. Entre ellas, una a favor de "bibliotecas e instituciones educativas sin ánimo de lucro para determinar si desean adquirir una obra", además deotras para ingeniería inversa de programas de ordenador, investigación sobreencriptación, protección de menores, etc. Estas excepciones conforman una lista cerrada, y cada una de ellas tiene sus propios criterios y está basada en políticas concretas. $\mathrm{H}$ ubo un intento de incluir una excepción general deelusión de las medidas tecnológicas basada en el fair use, pero finalmente fue rechazada.

Por lo que se refiere a la D irectiva europea de 2001, su objetivo es implementar el TD A a la vez que searmoniza en los Estados miembros la protección del derecho de autor. En concreto, esta directiva dedica su confuso y enrevesado artículo 6 a la protección de las medidas tecnológicas. Prohíbe tanto el acto personal de eludir las medidas tecnológicas (art. 6.1) como las denominadas actividades preparatorias (art. 6.2), pero, al contrario que la ley estadounidense, no hace distinción entre las medidas que protegen el acceso a las obras y las que protegen los derechos de autor. La relación entre derechos de autor y su excepciones está regulada en el apartado cuarto de este artículo, donde establece un sistema para establecer medidas voluntarias para definir el ámbito del derecho de autor: invita a las partes interesadas ( titulares de derechos y usuarios) a adoptar acuerdos para permitir que los usuarios se beneficien de las excepciones a los derechos deautor garantizadas por las legislaciones nacionales. Si dichos acuerdos no se producen, se requiere a los Estados miembros quetomen las medidas apropiadas para asegurar que los titulares delos derechos pongan a disposición de los beneficiarios de tales excepciones los medios para disfrutar de ellas. Pero todas estas medidas no tienen validez para las obras licenciadas en línea, como deja perfectamente claro el párrafo cuarto de este artículo, que establece que "Io dispuesto en los párrafos primero y segundo no será de aplicación a obras o prestaciones que se hayan puesto a disposición del público con arreglo a lo convenido por contrato, detal forma que personas concretas del público puedan acceder a ellas desde un lugar y en un momento que ella misma haya elegido". En términos muy generales, esto supone que queda prácticamente anulada la aplicación efectiva de los límites y excepciones al derecho de autor, ya que es precisamente ese tipo de uso el más habitual en el entorno digital. 
También Australia ha modificado muy recientemente su ley de derecho de autor para adaptarla al nuevo entorno tecnológico $y$, aunque también sigue en términos generales el esquema básico establecido por la DM CA, aporta algunas novedades muy interesantes en la regulación de las medidas tecnológicas. Sus características más significativas son las siguientes: su definición de medida tecnológica protegida es muy similar a la de las otras leyes analizadas, pero no distingue entre medidas que controlan el acceso y que protegen los derechos de autor; la tecnología para la elusión también es definida deforma similar, ya que sólo incluye a aquellos dispositivos o servicios cuyo único o principal objetivo o uso sea eludir las medidas tecnológicas; a diferencia de la D M CA y la D irectiva europea, no prohíbe el acto de elusión en sí mismo, sino únicamente las "actividades preparatorias". Pero lo más significativo de esta ley es su sistema de garantizar los límites y excepciones al derecho de autor, con su idea de "propósito permitido". Esta ley permite la fabricación y suministro de dispositivos y servicios anti-elusión si es para usarlos para un "propósito permitido", lo que sucede si dicho uso entra dentro de alguna de las limitaciones legales a los derechos de autor: copia de programas de ordenador para hacer productos interoperables, para corregir errores o para tests de seguridad; copia lícita llevada a cabo por bibliotecas, archivos, instituciones educativas, etc.

En cuanto a la legislación brasileña, los apartados I y II de su artículo 107, prohíben la alteración, supresión, modificación o inutilización de los dispositivos técnicos utilizados para evitar o restringir la copia o la comunicación pública de las obras. Aunque su contenido es excesivamente somero, especialmente si lo comparamos con las otras tres normas jurídicas analizadas, parece claro que esta ley sólo protege las medidas tecnológicas que controlan el uso (copia y comunicación pública) de las obras con derecho de autor, no el acceso. Pero su regulación es incompleta, ya que, al contrario que las otras leyes, no prevé ningún mecanismo para afrontar el conflicto entre la protección tecnológica y el disfrute de los límites a los derechos de autor.

No podemos hacer una valoración muy favorable deestas leyes, en especial de la D M CA y la D irectiva europea, ya que conducen a un excesiva protección de los derechos de autor en detrimento de los derechos de los usuarios, obstaculizando los usos educativos, culturales y de investigación de las obras intelectuales. Sin duda, la ley australiana es la que merece ser valorada de forma más positiva ya que, gracias a su original sistema de excepciones, consigue un mejor equilibrio entre los intereses de los titulares de los derechos (FernándezMolina, 2003).

\section{LAS LICENCIAS}

La aparición y desarrollo del entorno digital ha dado lugar a la progresiva sustitución de la venta por la licencia como principal medio para acceder a los recursos de información. $\mathrm{H}$ ay diferencias significativas entre vender una obra y licenciarla: la venta de una copia física de una obra implica la transferencia total de los derechos de propiedad sobreesa copia concreta de la obra, lo que permite al comprador diversos beneficios, como por ejemplo su reventa o su préstamo; en contraste, las licencias son contratos, es decir acuerdos privados que proporcionan una transferencia limitada de derechos para usar la obra.

Esta tendencia a que las transacciones relacionadas con la información digital estén gobernadas por contratos ha dado lugar a la aparición del problema de la posible anulación de los límites al derecho de autor a través de los términos y condiciones establecidos en tales contratos de licencia. N ormalmente, la libertad de contrato es la regla, y las restricciones contractuales la excepción, es decir, las partes son libres para negociar el contenido de los contratos de licencia siempreque permanezcan dentro de los límites del orden público. Sin embargo, las normas de orden público tienen muchas caras y varían de un país a otro, por lo quenos encontramos ante una cuestión clave: bajo qué circunstancias estaría justificada la limitación a la libertad de contratación cuando los acuerdos contractuales expanden excesivamente el derecho de autor (E Elkin-Koren, 1997). La respuesta a esta pregunta no es fácil, ya que no son habituales las disposiciones legales que establecen con claridad cuando tienen prioridad las normas legales de derecho de autor sobre las condiciones contractuales, por lo que habrá queanalizar en cada caso si ese concreto límiteal derecho de autor tiene prioridad sobre las estipulaciones contractuales o no. Es decir, habrá que ver en cada caso si un determinado límite al derecho de autor es imperativo o simplemente una regla "por defecto" (Lemley, 1995).

Esta difícil relación entre derecho de autor y derecho de contratos está siendo objeto de atención - aunque con muy diferente intensidad - en aquellos países que están liderando la reforma de los derechos de autor en el entorno digital: Estados Unidos, Unión Europea y 


\section{J. C arlos Fernández-M olina}

Australia. A continuación vamos a analizar los principales aspectos de este debate, aunque dedicando mucha más atención a la situación de Estados U nidos, dado quees el país donde este debate ha alcanzado mayor desarrollo.

D ebido a su estructura federal, la relación entre las normas sobre derecho de autor y las que regulan los contratos es especialmente compleja en Estados U nidos: mientras las primeras son competencia del Congreso, la legislación de contratos es responsabilidad de los diferentes estados, lo que plantea el problema de la preferencia de una sobre la otra. Así, el contenido de los contratos no sólo está limitado por las normas propias sobre validez de los contratos (fraude, coacción, etc.) aplicables en el entorno digital o en cualquier otro, sino quetambién existela posibilidad de quela L ey de D erecho de Autor pueda tener preferencia sobre los términos y condiciones establecidos en un contrato. En concreto, la sección 301 de su L ey de D erecho de Autor establece que una ley o derecho estatal serán anulados, dejando a la L ey de D erecho de Autor como única norma aplicable, si sedan dos circunstancias: a) ese "algo" debe caer bajo la materia de protección del derecho de autor como una obra original de autoría fijada en medio tangible de expresión; b) la ley del estado debe proporcionar derechos equivalentes a los proporcionados por el derecho deautor. Además de esta preferencia sobre la ley del estado, la preferencia también se puede conseguir a través de un análisis general basado en la Cláusula de Supremacía de la Constitución, enfoque cuya base está en plantearse si una ley de un estado supone un obstáculo para el cumplimiento de los propósitos y objetivos del Congreso. Si es así, la ley del estado será invalidada incluso aunque no se satisfagan los prerrequisitos de la sección 301 (Hardy, 1995).

Sin embargo, la doctrina general de sobrela preferencia de la ley federal sobre la estatal no ofrece directrices claras respecto a los contratos que derogan los derechos establecidos en la ley de derecho de autor. En cuanto a la Cláusula de Supremacía, todavía parece menos clara su aplicación a este contexto, dada la escasez de casos relevantes. Esta situación de indefinición, y la constatación de que a las bibliotecas y otros consumidores de obras digitales se les requiere de forma rutinaria que firmen acuerdos en los que renuncian a los límites al derecho de autor (incluyendo la doctrina de la primera venta, fair use o archivo/ preservación), ha llevado a los representantes de la comunidad bibliotecaria, entre otros, a solicitar que la sección 301 de la Ley de Derecho de Autor sea modificada para asegurar que las cláusulas de las licencias que anulan los privilegios de los consumidores concedidos por esta ley sean consideradas inválidas.

Pero, como hemos comentado previamente, la legislación sobre contratos cae bajo la responsabilidad de los estados, lo que nos lleva directamente a la polémica UCITA (U niform Computer Information Transactions Act). Esta ley, cuyo objetivo es dar uniformidad a las diversas normas legales de los diferentes estados, fue redactada en un principio por la $\mathrm{N}$ ational Conference of Commissioners on U niform State Laws (NCCUSL) y por el American Law Institute (ALI) para dar lugar a un nuevo artículo, el 2B, del U niform Comercial Code (UCC). Sin embargo, en sus intentos por modificar el U CC para dar cabida a las transacciones de información digital, N CCUSL y ALI encontraron muchas dificultades para integrar tales transacciones (de naturaleza intangible) con el ya existente artículo 2 del UCC que regula la venta de bienes tangibles. Como resultado, en abril de 1999 ALI retiró su apoyo a esta iniciativa y N CCU SL decidió dar un nuevo nombre a la propuesta del artículo 2B: U CITA, e intentar su implementación como una adición independiente a la legislación de cada estado ( $\mathrm{G}$ atten, 2002). U n análisis pormenorizado del contenido de esta ley, de sus consecuencias y de sus peripecias a lo largo de estos años sobrepasa con mucho los objetivos deeste artículo; no obstante, es imprescindible prestarle al menos una breveatención a sus aspectos fundamentales y al debateque ha provocado.

U CITA se basa en la premisa de la capacidad de las partes para determinar libremente las condiciones contractuales, de manera que, salvo ciertas excepciones, los términos y condiciones acordados por las partes rigen el contrato. Si no hay acuerdo sobre las condiciones de un contrato que implica "computer information transactions" (materiales con derecho de autor disponibles en línea, software, productos multimedia...), se aplican las disposiciones por defecto de U CITA. Esta ley supone un claro apoyo a la validez de los contratos aunque alteren de forman sustancial el equilibrio definido en la L ey de D erecho de Autor. Esta ruptura del equilibrio entre los intereses de los usuarios y los de los propietarios de los derechos ha originado la mayoría de las críticas de los expertos (Litman, 1998; Samuelson, 1998; Lemley, 1999; M cM anis, 1999; N eal, 2000; H eller, 2001), cuyos argumentos podemos resumir en: seextiende demasiado la definición de "licencia" para incluir transacciones que de otra forma podrían ser consideradas ventas; se facilita la validez de los acuerdos estándar usados habitualmente para regular los materiales digitales; 
servicios bibliotecarios tales como préstamo interbibliotecario, archivo y preservación de información digital están claramente amenazados. Tras considerables presiones por parte deacadémicos, grupos de consumidores y bibliotecarios, entre otros, se consiguió que U CITA incluyera la posibilidad (sección 105(b)) de que un contrato pueda no ser válido si contraviene la política pública; sin embargo, esta salvaguarda no proporciona la protección adecuada (Crews, 2001), ya que es demasiado confusa y genérica.

Aunque el NCCUSL aprobó UCITA el 29 de julio de 1999, su implantación en los estados está siendo muy complicada. De hecho, hasta el momento sólo dos estados la han convertido en ley: Virginia en el 2000 y $M$ aryland en el 2001 (aunque con algunas reformas). Además, otros estados ( N orth Carolina, West Virginia, lowa) han puesto en marcha iniciativas en sentido contrario, ya que han impulsado leyes (conocidas como "bomb-shelter") con el objetivo de bloquear la aplicación de U CITA a las empresas e individuos que residen en tales estados. Aunque no está clara la utilidad de estas leyes, lo que sí es evidente es el creciente sentimiento anti-U CITA que reflejan, lo que unido al bloqueo en su aprobación en diversos estados, permite pensar que el futuro de UCITA es bastantesombrío. Sin embargo, una adopción limitada de esta ley no significa necesariamente que sus disposiciones tengan un efecto limitado. Si la ley aplicableal contrato es de un estado que ha adoptado U CITA, UCITA puede aplicarse al contrato. A este respecto, este conflicto no sólo puede ocurrir dentro del entorno de los Estados U nidos, sino también en el resto del mundo: cualquier proveedor de información de cualquier país puede insertar en la licencia una cláusula de elección de ley aplicable designando U CITA como la ley que rija tal licencia de acceso y uso de la información (Ragueneau, 2002). En la actualidad, el debate sobre U CITA sigue abierto, con importantes empresas relacionadas con el software y la tecnología de la información apoyándola (incluidas M icrosoft, AOL 0 Business Software Alliance, y agrupadas como D igital Commerce Coalition), y con una amplia coalición en contra (que incluye a asociaciones de consumidores, instituciones de servicios financieros, profesionales de la tecnología, compañías de seguros y asociaciones de bibliotecarios) liderada por AFFECT (Americans for Fair Electronic Commerce Transactions).

En la U nión Europea, sin embargo, estos problemas casi no han sido discutidos, quizá por el hecho de que las normas de derecho de autor no son objeto de preferencia constitucional en ninguno de los Estados miembros. En algunos casos, poco frecuentes, el legislador ha evitado posibles conflictos al establecer expresamente que las normas de derecho de autor tienen prioridad sobre las condiciones contractuales en contrario. Estees el caso de las ya mencionadas directivas sobre programas de ordenador (U nión Europea, 1991) y protección jurídica de las bases de datos (U nión Europea, 1996), que contienen disposiciones que establecen que las estipulaciones contractuales que impidan a los usuarios llevar a cabo actos permitidos por la ley son nulas y sin valor. En concreto, la primera reconoce el derecho del usuario legítimo a hacer una copia de seguridad del programa (art. 5.2 y 3) o de decompilarlo para conseguir interoperabilidad (art. 6), estableciendo además que cualquier estipulación contractual contraria a estos derechos será nula y sin valor (art. 9.1). En términos parecidos se expresa el artículo 15 de la directiva sobre bases de datos en relación con el derecho del usuario legítimo a realizar determinadas reproducciones, extracciones o reutilizaciones desu contenido.

Sin embargo, la reciente $D$ irectiva sobre derecho de autor en la sociedad de la información (U nión Europea, 2001) cambia de criterio y no establece con claridad la relación entreel derecho de autor yel derecho de contratos. Sólo el considerando 45 lo toca levemente: "Ias excepciones y limitaciones a que se refieren los apartados 2, 3 y 4, del artículo 5 no deben ser un obstáculo para el establecimiento de relaciones contractuales encaminadas a asegurar una compensación equitativa a los titulares de los derechos de autor, en la medida permitida por el D erecho nacional". Además, tenemos el ya comentado último párrafo del artículo 6.4, en el que se deja claro que las limitaciones y excepciones al derecho de autor no son relevantes cuando la obra está protegida tecnológicamente y el usuario se ha obligado mediante contrato a no beneficiarse de tales excepciones. H ugenholtz (2000) critica duramente estos aspectos de la directiva y se sorprende de que lo establecido en las directivas de programas de ordenador y debases dedatos, ambas estableciendo la obligatoriedad de determinados derechos de los usuarios, se haya convertido de repente en algo irrelevante. A esterespecto, vale la pena recordar queEBLID A (2000), representando los intereses de las bibliotecas y sus usuarios, hizo una interesante solicitud (que desgraciadamente no fue tenida en cuenta) durante la tramitación de esta $\mathrm{D}$ irectiva: proponía quese añadiera un apartado al artículo 5 (el que regula las excepciones al derecho de autor) en el que se dejara claro que las estipulaciones contractuales contrarias a determinadas excepciones o limitaciones contempladas en el art. 5 fueran nulas de pleno derecho. 


\section{J. C arlos Fernández-M olina}

Por último, vamos a comentar brevemente el caso australiano, especialmente interesante porque su legislación no es tan contraria como las anteriores a los derechos de las bibliotecas y sus usuarios. H asta el momento, no se ha modificado su ley para afrontar el problema de la relación entre las licencias y las limitaciones y excepciones al derecho de autor. Sin embargo, ya se ha llevado a cabo un intenso trabajo de análisis de este problema, cuyo resultado es el reciente informe elaborado por el Copyright Law Review Committee (2002). Tras analizar la situación, este comité llega a dos importantes conclusiones: a) está claro que el equilibrio del derecho deautor está siendo modificado considerablemente; $\mathrm{y} b$ ) ninguna de las soluciones de la legislación interna (defensa de la competencia, protección del consumidor, etc.) es apropiada para afrontar este problema. En consecuencia, este comité decide hacer recomendaciones concretas para un cambio legislativo que permita afrontar con garantías este problema, en concreto propone que determinadas - no todas - excepciones y limitaciones al derecho de autor se consideren obligatorias, de forma que no puedan ser anuladas por los acuerdos privados. Pero, ¿ cuáles deberían ser obligatorias? La opinión del CLRC es queúnicamente aquéllas que son fundamentales para mantener el equilibrio del derecho de autor: las tradicionales defensas de fair dealing y las disposiciones relacionadas con las bibliotecas y archivos que permiten la reproducción y comunicación al público sin compensación dentro de unos límites especificados, y que reflejan el interés público en la educación, el libre flujo de información y la libertad de expresión; las más recientes excepciones que permiten las reproducciones de carácter temporal y transitorio; y, por último, mantener la integridad de los "propósitos permitidos", para impedir que el propietario de los derechos convierta en condición de acceso el que los usuarios no adquieran o usen un dispositivo o servicio de elusión de las medidas tecnológicas para un uso permitido. Estas recomendaciones deberán ser analizadas por el gobierno australiano en el contexto de su prometida revisión en el año 2003 de las reformas hechas a su L ey de D erecho de Autor en el 2000.

\section{CONCLUSIONES}

D ebido al gran desarrollo tecnológico de los últimos años, la normativa de derecho de autor está sufriendo una auténtica revolución, cuyo resultado es una excesiva protección de los intereses de los propietarios de los derechos, quese ben efician de varias capas acumulativas de protección: derecho deautor, protección tecnológica, protección legal de las medidas tecnológicas y legislación de contratos, en detrimento del dominio público y dela efectividad de los límites al derecho de autor. Como consecuencia, los propietarios de los derechos de autor tienen ahora una mayor capacidad para controlar el acceso a la información, ya que tienen un enorme poder para establecer sus propias reglas y construir una "legislación privada" que no necesariamente tendrá en cuenta el equilibrio establecido en las leyes de derecho de autor. En nuestra opinión, la mejor solución para afrontar los problemas del derecho de autor en el entorno digital no es sustituir el régimen regulador del derecho de autor por las condiciones de acceso a la información impuestas por los propietarios de la información. N o hay queolvidar quela información no es una simplemercancía que se puede comercializar: su uso crea un valor social añadido al influir en la opinión pública, las interacciones y la participación política, y proporciona un circuito de realimentación para que se produzca y reciba más información. Por tanto, es fundamental seguir manteniendo el tradicional equilibrio entrelos derechos delos autores, los de los comercializadores de las obrasy los de los ciudadanos. En estesentido, un buen ejemplo a seguir es el caso australiano, tanto en lo que se refierea su regulación de las medidas tecnológicas como a su propuesta de solución para el conflicto entrelicencias y límites al derecho de autor, aunque en este último caso habrá que esperar a ver si efectivamente se incluyen en la ley las propuestas del CLRC.

A rtigo recebido em 07-04-2003 eaceito para publicação em 29-04-2003

\section{REFERÊ N CIAS}

AU STRALIA. Copyright amendment: digital agenda- Act 2000. D isponível em: http:// scaletext.law.gov.au/html/ comact/ 10/6223/ top.htm>. Acesso em: 03 abr. 2003.

$B E L L, T$. W. Fair use vs. fared use: the impact of automated rights management on copyright's fair use doctrine. N orth Carolina Law Review, v. 76, p. 557-619, 1998. Disponível em: http:// www.tomwbell.com/writings/FullF ared.html. Acesso em: 03 abr. 2003.

BRASIL. Lei no 9.610, de 19 de fevereiro de 1998. Altera, atualiza e consolida a legislação sobre direitos autorais e dá outras providencias. Disponível em: <http://www.planalto.gov.br/ccivil_03/Leis/ L9610.htm>. Acesso em: 03 abr. 2003.

COPYRIGHT LAW REVIEW COM M ITTEE (Australia). Copyrightand contract, 2002. Disponível em: < http:// www.law.gov.au/ clrc.> . Acesso em: 03 abr. 2003.

CREWS, K. D. Looking ahead and shaping the future: Provoking change in copyright law. Journal of the Copyright Society of the USA, v. 49, n. 2, p. 549-584, 2001. 


\section{Protección tecnológica y contractual de las obras con derecho de autor: ¿H acia una privatización del acceso a la información?}

DEWERRA, J. The legal system of technological protection measures under the WIPO Treaties, the Digital M illennium Copyright Act, the European U nion directives and other national laws (Japan, Australia). In: ALAI CONGRESS: ADJUNCTS AND ALTERNATIVES TO COPYRIGHT, 2001, New York. Disponível em: < http:// www.law.columbia.edu/conferences/2001/Reports/dewerra.doc. $>$. Acesso em: 3 abr. 2003.

EBLIDA. Respuesta de EBLID A a la propuesta de directiva relativa a la armonización de determinados aspectos de los derechos de autor y derechos afines en la sociedad de la información, 2002. D isponível em: < http:// www.eblida.org/topics/position/response october_es. htm.> . Acesso em: 03 abr. 2003.

ELKIN-KOREN, N. Copyright policy and the limits of freedom of contract. Berkeley Technology Law Journal, v. 12, n. 1, 1997 Disponível em: < http:// www.law. berkeley.edu/journals/btlj/articles/ 12_1/Elkin-Koren/html/reader.html. Acesso em: 03 abr. 2003.

EST AD OS U N ID OS. D igital M illennium Copyright Act 1998. D isponible en: http:// www.loc.gov/ copyright/ legislation/ hr2281.pdf. Acesso em: 03 abril 2003.

FERNÁNDEZ-M OLINA, J.C. Laws against the circumvention of copyright technological protection. J ournal of D ocumentation, v. 59, n. 1, p. 41-68, 2003.

; PEIS, E. The moral rights of authors in the age of digital information. J ournal of the American Society for I nformation Science and Technology, v. 52, n. 2, p. 109-117, 2001.

GARROTE, I. EI derecho de autor en Internet: la directiva sobre derechos de autor y derechos afines en la sociedad de la información. Granada : Comares, 2001.

GATTEN, J. N. The politics of the U niform Computer Information Transaction Act in digital information policy development. Online Information Review, v. 26, n. 6, p. 385-391, 2002.

GORDON, W. J. Fair use as market failure: a structural and economic analysis of the Betamax case and its predecessors. Columbia Law Review, v. 80, n. 8, p. 1600-1657, 1982.

GUIBAULT, L. M. C. R. Contracts and copyright exemptions. In: HUGENHOLTZ, P. B. (Ed.). Copyright and electronic commerce: legal aspects of electronic copyright management. The Hague: Kluwer Law International, 2000. p. 125-163.

H ARDY, I. T. Contracts, copyright and preemption in a digital world. Richmond Journal of $L$ aw and Technology, v. 1, n. 1, 1995. Disponível e: < http://law.richmond.edu/jolt//vli1/hardy.html.>. Acesso em: 03 abr. 2003.

HELLER, J. S. UCITA: still crazy after all these years, and still not ready for prime time. The Richmond Journal of $L$ aw and Technology, v. 8, n. 1, 2001. Disponível em:<http://law.richmond.edu/jolt/ noflash_site/lthome.htm. Acesso em: 03 abr. 2003.

HUGENHOLTZ, P. B. Why the copyright directive is unimportant, and possibly invalid. European Intellectual Property Review, v. 22, n. 11, p. 409-505, 2000.

KOELM AN, K. J. A hard nut to crack: The protection of technological measures. European Intellectual Property Review, v. 22, n. 6, p. 272288,2000 .

LEM LEY, M . A. Intellectual property and shrinkwrap licenses. Southern California Law Review, v. 68, n. 5, p. 1239-1294, 1995.
LEM LEY, M . A. Beyond preemption: The law and policy of intellectual property licensing. California Law Review, v. 87, n. 1, p. 111-172, 1999.

LITM AN, J. The tales that Article 2B tells. Berkeley Technology Law Journal, v. 13, n. 3, 1998. Disponível em: <http:// www.law.berkeley.edu/journals/btlj/ articles/vol13/ Litman/html/ reader.html.>. Acesso em: 03 abr. 2003.

M CM AN IS, C. R. The privatization (or shrink-wrapping) of American copyright law. California Law Review, v. 87, n. 1, p. 173-190, 1999.

MERGES, R. P. The end of friction? Property rights and contract in the $\mathrm{N}$ ewtonian world of on-line commerce. Berkeley T echnology Law Journal, v. 12, n. 1, 1997. Disponível em:<http:// www.law. berkeley.edu/journals/btlj/ articles/12_1/ M erges/html/ reader.html.>. Acesso em: 03 abr. 2003.

NACIONES UNIDAS. Declaración U niversal de los D erechos H umanos, 1948. Disponível em:<http://www.un.org/spanish/aboutun/ hrights.htm. >. Acesso em: 03 abr. 2003.

NEAL, J. G. The fight against U CITA. Library J ournal, v. 125, n. 15, p. 36-38, 2000 .

OM AN, R. Intellectual property after the U ruguay R ound. Journal of the Copyright Society of the U.S.A., v. 42, n. 1, p. 18-38, 1994.

OMC. Acuerdo sobre los aspectos de los derechos de propiedad intelectual relacionados con el comercio. Anexo $1 \mathrm{C}$ del Acuerdo de $M$ arrakech por el que se establece la Organización Mundial del Comercio de 15 de abril de 1994. Disponível em:< http:// www.wto.org/spanish/docs_s/legal_s/27-trips.pdf.> . Acesso em: 03 abr. 2003.

OM PI. Convenio deBerna para la protección delas obras literarias y artísticas: (Acta de París del 24 de julio de 1971 y enmendado el 28 de septiembre de 1979). Disponível em: < http:// www.wipo.int/ clea/docs/ es/ wo/ wo001es.htm.> Acesso em: 03 abr. 2003.

. Tratado de la O M PI sobre derecho de autor, 1996. Disponível em: http:// www.wipo.int/clea/ docs/ es/ wo/ wo033es.htm. Acesso em: 03 abr. 2003.

Tratado dela O M PI sobreInterpretación o Ejecución y Fonogramas, 1996. Disponível em: < http:// www. wipo.int/clea/docs/ es/wo/ wo034es.htm. Acesso em: 03 abr. 2003.

O 'ROU RKE, M. A. Fencing cyberspace: drawing borders in a virtual world. M innesota Law Review, v. 82, n. 3, p. 609-704, 1998.

RAGUENEAU, A.D. UCITA and the impact on European copyright law: A choice of law analysis. Journal of the Copyright Society of the USA, v. 49, n. 4, p. 1057-1116, 2002.

SAM UELSON, P. Does information really have to be licensed? Communications of the ACM , v. 41, n. 9, p. 15-20, 1998.

UNIÓN EUROPEA. Directiva del Consejo de 14 de mayo de 1991 sobrela protección jurídica deprogramas deordenador (91/250/CEE), D OCE 17.05.1991, L122. [S. I.], 1991.

Directiva 96/9/CE del Parlamento Europeo y del Consejo de 11 demarzo de 1996 sobre la protección jurídica de las bases de datos, D OCE 27.03.1996, L77. [S. I.], 1996.

Directiva 2001/29/CE del Parlamento Europeo y del Consejo de 22 demayo de2001 relativa a la armonización de determinados aspectos delos derechos de autor y derechos afines en la sociedad dela información, DOCE 22.6.2001, L167. [S. I.], 2001. 